\title{
Contribuições sociológicas para o desenvolvimento rural sustentável: Uma revisão integrativa da literatura
}

\author{
Sociological contributions to sustainable rural development: An integrative review of the
}

literature

Contribuciones sociológicas al desarrollo rural sostenible: Una revisión integrativa de la

literatura

Recebido: 10/05/2021 | Revisado: 16/05/2021 | Aceito: 04/06/2021 | Publicado: 18/06/2021

Ceyça Lia Palerosi Borges

ORCID: https://orcid.org/0000-0003-2818-3569

Universidade Estadual do Oeste do Paraná, Brasil

E-mail: ceyca.borges@uffs.edu.br

Jonas Felipe Recalcatti

ORCID: https://orcid.org/0000-0002-4414-7173

Universidade Estadual do Oeste do Paraná, Brasil

E-mail: jonasrecalcatti_bio@hotmail.com

Márcia Hanzen

ORCID: https://orcid.org/0000-0002-4882-7010

Universidade Estadual do Oeste do Paraná, Brasil

E-mail: marciahanzen@hotmail.com

Nândri Cândida Strassburger

ORCID: https://orcid.org/0000-0002-2301-6166

Universidade Estadual do Oeste do Paraná, Brasil

E-mail: nandricandida@gmail.com

\begin{abstract}
Resumo
Por meio de uma revisão integrativa, esta pesquisa objetivou analisar a produção científica brasileira que discute o entendimento da lógica do Desenvolvimento Sustentável amparada nos estudos e pesquisas da sociologia e verificar se o âmbito rural é contemplado nestes estudos. Foram realizadas buscas criteriosas na base Web of Science e assim selecionados 19 trabalhos. São analisados, ano de publicação, idioma, fonte e tipo de documento, áreas de pesquisa e palavras-chave. Dois grandes temas foram identificados nos trabalhos recuperados sendo eles: Políticas Públicas associadas ao Desenvolvimento Rural Sustentável e Gestão associadas ao Desenvolvimento Rural Sustentável evidenciando como os estudos na sociologia compreendem esta temática. No Brasil, a região da Amazônia é destaque nos estudos recuperados, voltados a projetos e políticas públicas voltados ao desenvolvimento sustentável. O interesse dos estudos por esta região do Brasil só reforça sua importância para a sustentabilidade do país.
\end{abstract}

Palavras-chave: Políticas públicas; Desenvolvimento rural sustentável; Sociologia.

\begin{abstract}
This research, by means of integrative revision, has as its objective to analyze the Brazilian scientific production which debates the understanding of Sustainable Development's logics supported by sociology studies and research and to verify whether the rural scope is contemplated within those studies. Thorough research was conducted in Web of Science's base and thus 19 papers were selected. Year of publication, language, source and type of document, research area and key words are analyzed. Two large themes were identified in the recovered papers, those being: Public Policies associated with Rural Sustainable Development and Management Practices associated with sustainable rural development making evident how studies in sociology comprehend this theme. In Brazil, the Amazon region has emphasis in the recovered studies, directed at projects and public policies directed at sustainable development. The interest in studies in this region of Brazil only reinforces its importance to the country's sustainability.
\end{abstract}

Keywords: Public policies; Rural sustainable development; Sociology.

\section{Resumen}

A través de una revisión integradora, esta investigación tuvo como objetivo analizar la producción científica brasileña que discute la comprensión de la lógica del Desarrollo Sostenible sustentada en estudios e investigaciones sociológicas y verificar si el ámbito rural está incluido en estos estudios. Se realizaron búsquedas cuidadosas en la base de datos de Web of Science y, por lo tanto, se seleccionaron 19 trabajos. Se analizan año de publicación, idioma, fuente y tipo de documento, áreas de investigación y palabras clave. En las obras recuperadas se identificaron dos 
grandes temas: Políticas Públicas asociadas al Desarrollo Rural Sustentable y Gestión asociada al Desarrollo Rural Sustentable, mostrando cómo los estudios en sociología entienden este tema. En Brasil, la región amazónica se destaca en los estudios recuperados, dirigidos a proyectos y políticas públicas orientadas al desarrollo sostenible. El interés de los estudios en esta región de Brasil solo refuerza su importancia para la sostenibilidad del país.

Palabras clave: Políticas públicas; Desarrollo rural sostenible; Sociología.

\section{Introdução}

No meio rural, a proposta do agronegócio que visa sobretudo a produção em massa e o acúmulo de capital, transformou toda a lógica de trabalho dos agricultores, não somente em relação ao conjunto de práticas e tecnologias utilizadas para atender as demandas do mercado, como também a exploração desmedida dos recursos naturais.

Ao pensar apenas em crescimento econômico, a sustentabilidade do meio rural sofreu perdas irreparáveis, ao negligenciar o contexto social, cultural e ambiental da vida no campo. Para Boff (2015, p. 128), “uma sociedade só pode ser considerada sustentável se ela mesma, por seu trabalho e produção, tornar-se mais e mais autônoma. Porém, ao invés disso, os agricultores deixaram de ser donos do seu próprio negócio, e se tornaram reféns dos pacotes tecnológicos (insumos, máquinas e sementes) e não mais protagonistas das suas histórias.

No início do século XX, os danos causados a natureza e consequentemente a toda a humanidade trouxe um repensar da sociedade pautado na sustentabilidade. Para o alcance de um desenvolvimento sustentável, não se pode atrelar apenas à ideia de acúmulo de capital, e sim considerar o bem comum, tanto para a sociedade como para o meio ambiente. Sachs (1995, p. 33), considera que "é necessário tratar simultaneamente os cinco temas, sendo eles a paz, economia, meio ambiente, justiça e democracia, tomando as condições sociais como ponto de partida dos esforços em prol do desenvolvimento"

Nesse contexto, considerando o setor agropecuário, Martins (2001) cita o documento "Diretrizes de Política Agrária e Desenvolvimento Sustentável para o Brasil” apresentado em 1994 pela FAO/INCRA, que enfatiza a dimensão social da sustentabilidade, e propõe que para alcança-lo, a sociedade brasileira deveria optar pelo fortalecimento e expansão da agricultura familiar através de um programa de políticas públicas como forma de reduzir os problemas sociais, englobando políticas agrícolas, industriais e agrárias de curto, médio e longo prazo.

Para Schneider (2010), a capacidade de inovação dos agricultores familiares e sua interação com as instituições locais são fundamentais para que possam ampliar a geração e agregação de valor, assim como reduzir custos de transação e estimular economias de escopo.

Estudar as perspectivas e os focos de estudo de cada trabalho desenvolvido na temática do desenvolvimento no Brasil na última década, é ter bem claro para onde se fixa o olhar dos estudiosos do tema nas diversas áreas, e nesse estudo, a sociologia possibilitará a compreensão desta temática. Assim saber-se-á se novos paradigmas do desenvolvimento estão sendo contemplados nestes estudos, ou se continuamos a replicar trajetórias passadas, mudando apenas a roupagem do objeto.

Para tanto, através da revisão integrativa, esta pesquisa tem como objetivo analisar a produção científica brasileira que discute o entendimento da lógica do Desenvolvimento Sustentável, amparada nos estudos e pesquisas da Sociologia e verificar se e como o âmbito rural é contemplado nestes estudos.

\section{Metodologia}

Esta pesquisa utilizou a revisão bibliográfica para atingir o objetivo proposto neste estudo. O método utilizado da revisão bibliográfica nesta pesquisa foi a revisão integrativa que segundo Mendes et al (2008), “a revisão integrativa consiste na construção de uma análise ampla da literatura, contribuindo para discussões sobre métodos e resultados de pesquisas, assim como reflexões sobre a realização de futuros estudos". No método de revisão integrativa é primordial que o rigor metodológico seja seguido com clareza na forma de apresentação dos resultados, para facilitar a interpretação dos dados. 
Nesta pesquisa foi estabelecida a estratégia de busca na base Web of Science por ser uma base multidisciplinar com referência em publicações internacionais com destaque na área da ciência sociais, com boa expressão de artigos, cobrindo aproximadamente 12.000 periódicos desde 1945. A busca nesta base ocorreu no período de novembro e dezembro de 2019.

Para analisar o tema do Desenvolvimento Sustentável tendo como foco estudos da sociologia no Brasil foram estabelecidos trios de descritores para que nas buscas retornassem trabalhos que contivessem tanto o termo desenvolvimento sustentável, sociologia e Brasil. Para tanto foi utilizado o operador booleano and entre esses três termos. A fim de acessar a maior parte de trabalhos que abordam o tema pesquisado, a busca na base escolhida neste estudo incluiu o uso de termos alternativos que possuíam o mesmo significado nas línguas portuguesa, espanhola e inglesa. Dessa forma, ao realizar a busca dos trabalhos nas bases científicas selecionadas, foram utilizados os seguintes descritores: Sociology and sustentability and Brazil, Sociology and "sustainable development" and Brazil, Sociologia and "Desenvolvimento Sustentável" and Brazil, Sociologia and Sustentabilidade and Brazil, Sociología and sustentabilidad and Brazil e Sociología and "desarollo sustentable" and Brazil .

Os parâmetros de inclusão/exclusão para a seleção dos artigos na base foram o período de busca, local da busca nos documentos e tipo de documento. O período da busca foi de 1987 a 2019, pelo fato de compreende-se que as discussões em torno do Desenvolvimento Sustentável passaram a se intensificar, período marcado pelo surgimento deste conceito no Relatório de Brundtland em Copenhagem em 1987.

Os descritores foram procurados nos títulos, resumos ou palavras-chave e os tipos de documentos pesquisados foram artigos científicos e reviews. Também houve o emprego da dupla checagem, na qual duas pessoas realizam os procedimentos da revisão integrativa para posterior comparação e discussão dos resultados. Após a leitura dos trabalhos capturados, foram estabelecidas duas categorias de análise nos quais os trabalhos foram classificados, sendo elas: Políticas Públicas como eixo do Desenvolvimento Rural Sustentável e Gestão como eixo do Desenvolvimento Rural Sustentável. Após a categorização seguiuse para a análise e interpretação dos dados.

\section{Resultados e Discussão}

\subsection{Análise quantitativa dos estudos sociológicos sobre Desenvolvimento Rural Sustentável}

Na primeira busca realizada na base científica da Web of Science foram recuperados 71 documentos. Contudo, nem todos os trabalhos recuperados tratavam sobre o tema desta pesquisa. Desse total, 4 trabalhos estavam repetidos em mais descritores, 36 não abordavam sobre o tema desenvolvimento sustentável e 12 tratavam sobre o tema do desenvolvimento sustentável, porém não no âmbito rural. Sendo assim, esses 52 trabalhos foram excluídos, ficando um total de 19 estudos que são o foco desta pesquisa.

O par de descritores Sociology and "sustainable development" é o que obteve o maior número de trabalhos encontrados, 18 no total, seguido pelo descritor Sociologia and "Desenvolvimento Sustentável" que resultou em apenas um trabalho. Observa-se que o par de descritores da língua inglesa foi o que resultou em maior número de registro sobre o tema pesquisado.

O Gráfico 1, a seguir, apresenta a quantidade de trabalhos discutidos na sociologia sobre desenvolvimento rural sustentável por ano de publicação. 
Gráfico 1 - Relação da quantidade de artigo por ano de publicação.

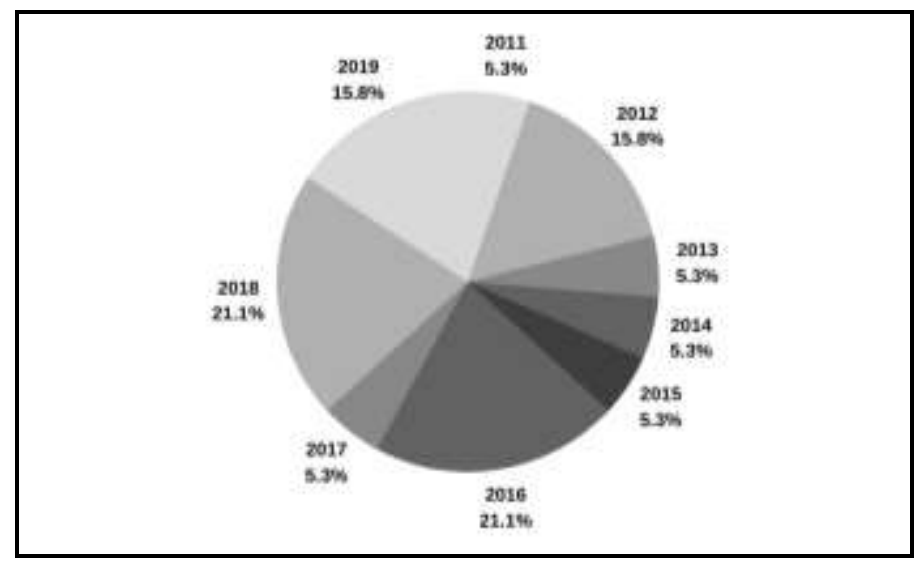

Fonte: Autores (2020).

O ano que houve o maior número de publicações foram 2018 e 2016 com 21,1 \% do total dos artigos publicados, seguidos pelos anos de 2012 e 2019 com 15,8\% e em seguida, os anos com o menor número de publicações foram 2011, 2013, 2014, 2015 e 2017. É importante ressaltar que a busca nas bases científicas foram após 1987, porém foi a partir de 2011 que os primeiros trabalhos surgiram nesta busca, demonstrando o quão recente são as discussões sobre a temática do Desenvolvimento Rural Sustentável nos estudos da sociologia.

O Gráfico 2 a seguir mostra a quantidade de trabalhos por país de origem da publicação.

Gráfico 2 - Quantidade de trabalho por país de origem da publicação.

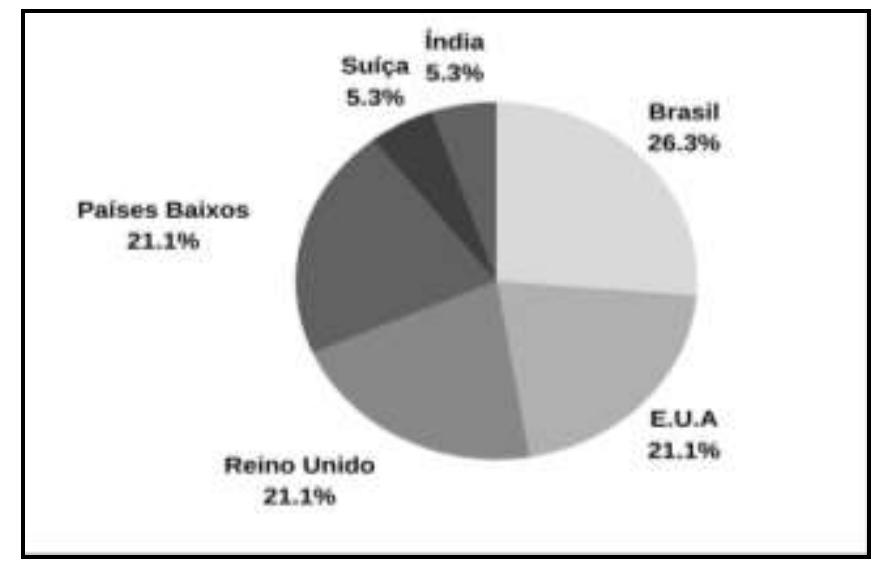

Fonte: Autores (2020).

O país que obteve o maior número de publicações, com um percentual de 26,3\%, foi o Brasil, seguido pelos Países Baixos, Reino Unido e E.U.A que apresentaram cada um 21,1\% dos trabalhos. A Suíça e a Índia apresentaram 5,6\% dos trabalhos investigados. Observa-se, portanto que, a maioria dos trabalhos recuperados nesta pesquisa foram publicados no Brasil, demonstrando o interesse por esta temática nos estudos da sociologia neste país.

Em relação ao idioma, 78,9\% são em inglês e apenas $21,1 \%$ são na língua portuguesa. A predominância de trabalhos na língua inglesa é esperada, pois é a língua em que os artigos científicos são mais publicados.

A seguir, o Gráfico 3 mostra a relação de trabalhos publicados por área de pesquisa. 
Gráfico 3 - Relação de trabalhos por área de pesquisa.

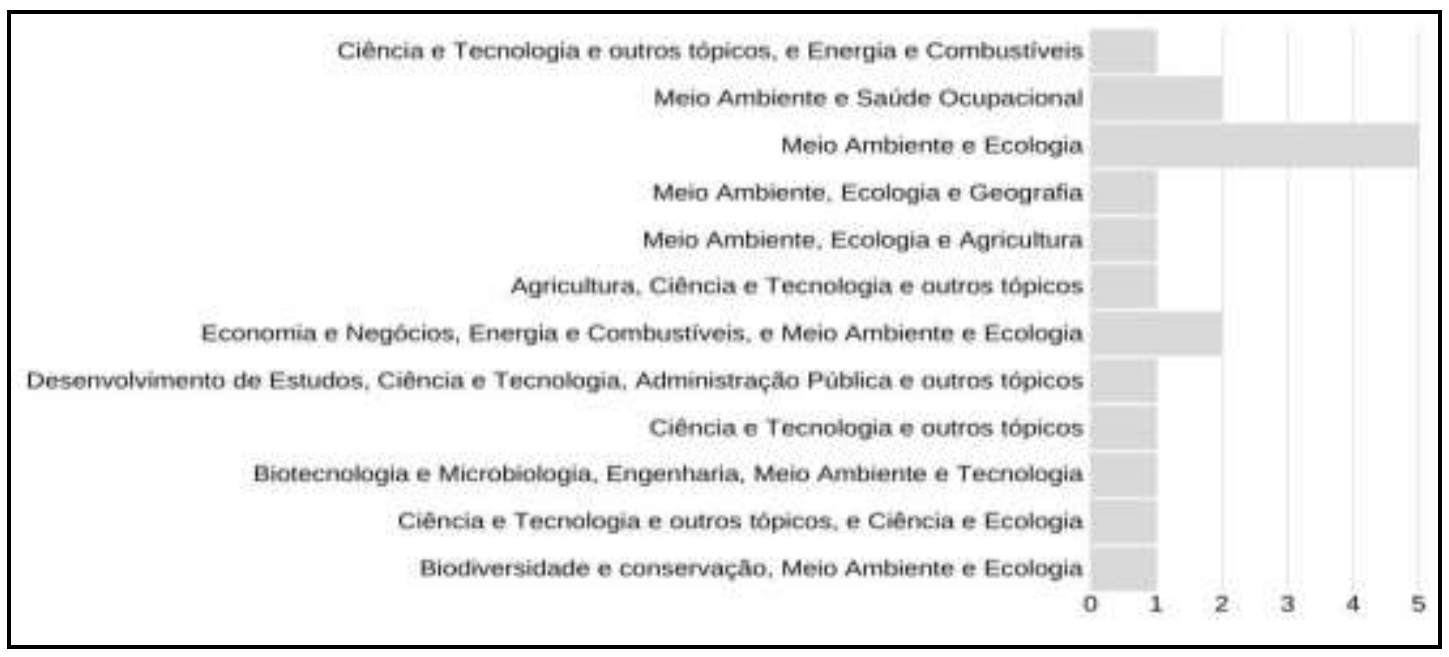

Fonte: Autores (2020).

Os trabalhos recuperados estiveram presentes em 12 áreas de pesquisa, sendo a área que mais se destacou foi Meio Ambiente e Ecologia com 5 trabalhos, seguida pelas áreas Meio Ambiente e Saúde Ocupacional e Economia e Negócios, ambas com 4 trabalhos. As demais áreas apresentaram apenas um trabalho em cada uma. Diante da temática desta pesquisa, não foi surpreendente que as áreas que mais se enquadram os trabalhos estejam relacionadas ao meio ambiente e a economia. O curioso é que apesar de um dos pares dos descritores trazerem a sociologia no amago das discussões, esta área de pesquisa não foi evidenciada nos trabalhos recuperados.

As palavras-chave dos 19 trabalhos foram analisadas em um diagrama de nuvem de palavras conforme sistematizado na Figura 1, a seguir:

Figura 1 - Nuvem de palavras das palavras-chave.

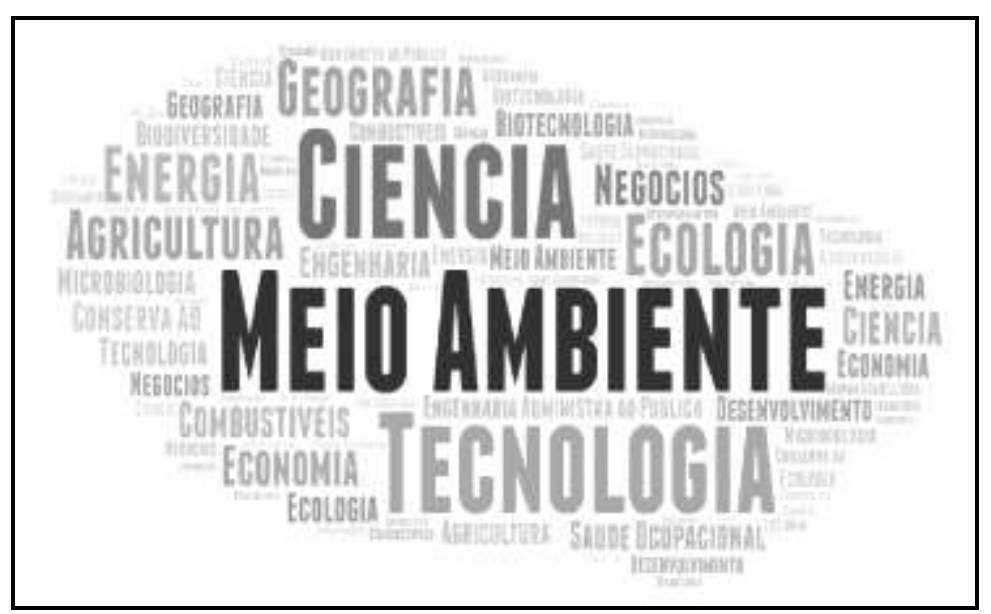

Fonte: Autores (2020).

As palavras-chave que mais se destacaram foram meio ambiente, ciência e tecnologia, evidenciando a relevância destes temas nos estudos da sociologia que abordam a temática do Desenvolvimento Rural Sustável.

O tópico a seguir abrange a análise e interpretação dos dados qualitativos dos 19 trabalhos selecionados na revisão. 


\subsection{Análise qualitativa dos estudos sociológicos sobre Desenvolvimento Rural Sustentável}

\subsubsection{Análise dos trabalhos que destacaram as Políticas Públicas como eixo do Desenvolvimento Rural Sustentável.}

No Quadro 1 foram selecionados 10 dentre os 19 trabalhos nos quais as Políticas Públicas eram o eixo do Desenvolvimento Rural Sustentável.

Quadro 1 - Políticas Públicas associadas ao Desenvolvimento Rural Sustentável.

\begin{tabular}{|c|c|c|}
\hline TÍTULO & OBJETIVO & METODOLOGIA \\
\hline $\begin{array}{l}\text { 04- A sustentabilidade dos } \\
\text { financiamentos do PRONAF para a } \\
\text { agricultura familiar. }\end{array}$ & $\begin{array}{l}\text { O trabalho analisa de que maneira a questão da } \\
\text { sustentabilidade se reflete na formulação e na incorporação } \\
\text { das políticas públicas de crédito rural no Brasil }\end{array}$ & $\begin{array}{l}\text { Empírico - Qualitativa- Estudo } \\
\text { de caso Território Meio Oeste } \\
\text { Contestado } \\
\text { localizado na mesorregião } \\
\text { oeste do Estado de Santa } \\
\text { Catarina - Análise documental, } \\
\text { entrevista semi estruturada } \\
\text { com os atores envolvidos. }\end{array}$ \\
\hline $\begin{array}{l}\text { 08- Challenges for sustainable } \\
\text { development in Brazilian } \\
\text { Amazonia }\end{array}$ & $\begin{array}{l}\text { O presente artigo examina os desafios ao desenvolvimento } \\
\text { sustentável na Amazônia brasileira. }\end{array}$ & $\begin{array}{l}\text { Teórico - revisão de literatura } \\
\text { sobre o tema. }\end{array}$ \\
\hline $\begin{array}{l}\text { 09- Curbing enthusiasm for } \\
\text { Brazilian agribusiness: The use of } \\
\text { actor-specific assessments to } \\
\text { transform sustainable development } \\
\text { on theground. }\end{array}$ & $\begin{array}{l}\text { Destaca as limitações estruturais que impedem o progresso } \\
\text { agrícola e explica por que é necessário superar esses } \\
\text { impedimentos em um estudo de caso do Brasil, um dos } \\
\text { principais exportadores agrícolas do mundo }\end{array}$ & $\begin{array}{l}\text { Empírico- Estudo de caso } \\
\text { regiões Norte e Centro-Oeste } \\
\text { do Brasil, produtores de soja }\end{array}$ \\
\hline $\begin{array}{l}\text { 10- Development projects for small } \\
\text { rural communities in the Brazilian } \\
\text { Amazon region as potential } \\
\text { strategies and practices of climate } \\
\text { change adaptation. }\end{array}$ & $\begin{array}{l}\text { A pesquisa tem como objetivo identificar, descrever e } \\
\text { avaliar fatores presentes em projetos de desenvolvimento } \\
\text { sustentável para pequenas comunidades rurais (Projetos de } \\
\text { Demonstração Tipo A - PDA e Alternativas a Projetos de } \\
\text { Desmatamento e Queimados - PADEQ), já } \\
\text { implementados, para reconhecer seu potencial uso como } \\
\text { estratégias de adaptação às mudanças climáticas em } \\
\text { pequenas comunidades rurais da região amazônica. }\end{array}$ & $\begin{array}{l}\text { Empírico - Estudo de caso - } \\
\text { quinze projetos nos estados de } \\
\text { Rondônia, Pará e Mato Grosso, } \\
\text { foram desenvolvidas por meio } \\
\text { de análise de documentos, } \\
\text { visitas técnicas e entrevistas } \\
\text { com stakeholders de três } \\
\text { projetos sobre percepção, } \\
\text { vulnerabilidade e capacidade } \\
\text { de adaptação da comunidade. }\end{array}$ \\
\hline $\begin{array}{l}\text { 14- Intensification in agriculture- } \\
\text { forest frontiers: Land use responses } \\
\text { to development and conservation } \\
\text { policies in Brazil. }\end{array}$ & $\begin{array}{l}\text { O objetivo deste estudo é entender o tempo e os padrões } \\
\text { espaciais da intensificação de culturas e pastagens nas } \\
\text { fronteiras agricultura-floresta no contexto de mudanças nas } \\
\text { políticas de conservação e desenvolvimento rural. }\end{array}$ & $\begin{array}{l}\text { Empírico - estudo de caso no } \\
\text { Mato Grosso - análise } \\
\text { econométrica de dados de } \\
\text { pesquisas remotas e sensoriais }\end{array}$ \\
\hline $\begin{array}{l}\text { 15- Política energética na } \\
\text { Amazônia: a UHE estreito e os } \\
\text { camponeses tradicionais de } \\
\text { Palmatuba/Babaçulândia (TO). }\end{array}$ & $\begin{array}{l}\text { Analisar a política energética brasileira frente ao } \\
\text { crescimento econômico nacional e como a construção de } \\
\text { barragens influenciou o modo de vida de comunidades } \\
\text { atingidas na Amazônia, sobretudo no processo de } \\
\text { reivindicação das indenizações. }\end{array}$ & $\begin{array}{l}\text { Empírico - estudo de caso - } \\
\text { comunidade ribeirinha do rio } \\
\text { Tocantins de Palmatuba, em } \\
\text { Babaçulândia/TO, atingida } \\
\text { pelo reservatório da UHE de } \\
\text { Estreito }\end{array}$ \\
\hline $\begin{array}{l}\text { 17- The Displacement of } \\
\text { Insufficiently 'Traditional' } \\
\text { Communities:Local Fisheries in the } \\
\text { Pantanal. }\end{array}$ & $\begin{array}{l}\text { Analisar como os ambientalistas usaram a Política } \\
\text { Nacional para o Desenvolvimento Sustentável dos Povos e } \\
\text { Comunidades Tradicionais - PNDSPCT para justificar o } \\
\text { deslocamento da população local, alegando que ela não se } \\
\text { encaixa em nenhuma comunidade tradicional, categoria, e } \\
\text { em vez disso, deve ser chamado de 'pobre rural'. }\end{array}$ & $\begin{array}{l}\text { Empírico- Estudo de caso - } \\
\text { Pantanal - estudo etnográfico. }\end{array}$ \\
\hline $\begin{array}{l}\text { 21- Vulnerabilidade } \\
\text { socioambiental, redução de riscos } \\
\text { de desastres e construção da } \\
\text { resiliência - lições do terremoto no } \\
\text { Haiti e das chuvas fortes na Região } \\
\text { Serrana, Brasil. }\end{array}$ & $\begin{array}{l}\text { Colaborar para a reflexão sobre a necessidade de uma nova } \\
\text { abordagem sociológica no Brasil, que não apenas utilize os } \\
\text { índices como instrumentos de análise para a pesquisa, mas } \\
\text { que reflita sobre como a sociedade foi reorientada e } \\
\text { reconfigurada a partir deles. }\end{array}$ & Teórico \\
\hline $\begin{array}{l}\text { 07- Beyond commonplace biofuels: } \\
\text { Social aspects of ethanol. }\end{array}$ & $\begin{array}{l}\text { Contribuir para o desenvolvimento de estruturas sociais a } \\
\text { serem usadas na avaliação do impacto do etanol. }\end{array}$ & $\begin{array}{lll}\begin{array}{l}\text { Revisão } \\
\text { literatura }\end{array} & \text { sistemática } & \text { da } \\
\end{array}$ \\
\hline $\begin{array}{l}\text { 16- Rural Economy and Bioethanol } \\
\text { Production. }\end{array}$ & $\begin{array}{l}\text { Demonstra de maneira sustentável o funcionamento da } \\
\text { economia da máquina - isto é, a agricultura - por meio da } \\
\text { defesa do uso eficiente dos recursos nas fazendas e de suas } \\
\text { associações, juntamente com o apoio à transição para um } \\
\text { nível baixo. economia de carbono, graças ao progresso na } \\
\text { produção de bioetanol }\end{array}$ & $\begin{array}{l}\text { Empírico - estudo de caso - } \\
\text { fazendas comunitárias nos } \\
\text { países como a Romênia ou a } \\
\text { Bulgária (produção de } \\
\text { biocombustíveis) }\end{array}$ \\
\hline
\end{tabular}


Fonte: Autores (2020).

Na categoria observadas no Quadro 1, foram analisados os estudos nos quais abordavam as Políticas Públicas como um importante instrumento para o Desenvolvimento Rural Sustentável. Três trabalhos desta categoria apresentam discussões teóricas $(8,21,7)$ sobre o desafio do desenvolvimento sustentável, a importância de uma nova abordagem sociológica, e o impacto do etanol nas estruturas sociais. Os sete trabalhos restantes $(4,9,10,14,15,17,16)$ são empíric os e analisam através de estudo de caso temas como: formulação de políticas públicas no crédito rural, sobre o desafio de desenvolvimento sustentável, políticas públicas no contexto da conservação e desenvolvimento rural, sobre política energética, sobre política pública para o desenvolvimento sustentável de povos tradicionais, e sobre a produção do etanol. Ao verificar a metodologia desses trabalhos, nota-se que foram utilizados diferentes instrumentos de coleta e análise de dados tais como, análise documental, entrevistas, estudo etnográfico, e de revisão de literatura, sendo que em muitos trabalhos utilizaram dois os mais instrumentos para coletar e analisar os dados estudados.

Dos 10 trabalhos desta categoria de análise 8 foram pesquisas realizadas no Brasil, nos estados de Santa Catarina, Rondônia, Pará, Mato Grosso e Tocantins. Outro estudo fez uma abordagem que analisou a região Serrana do Rio de Janeiro e o Haiti. Ainda nesta categoria foi investigado um caso na Romênia.

Um destes trabalhos ${ }^{(4)}$ analisa de que maneira a questão da sustentabilidade se reflete na formulação e na incorporação das políticas públicas de crédito rural no Brasil. O enfoque teórico-metodológico baseou-se na abordagem neo-institucionalista denominada "três is" e toma como fundamentação empírica o funcionamento das políticas de crédito rural presentes no território do Meio Oeste Contestado (SC), com destaque para o Programa Nacional de Fortalecimento da Agricultura Familiar (Pronaf). Percebe-se que a incorporação da sustentabilidade já integra as orientações gerais do Pronaf. Tais constatações indicam que ainda há um longo caminho a se trilhar para que a ideia da sustentabilidade seja plenamente incorporada no Pronaf, reorientando suas normas operacionais e as condutas dos atores rumo ao desenvolvimento sustentável.

Outro trabalho ${ }^{(8)}$ analisa os desafios para o desenvolvimento sustentável na Amazônia Brasileira, inferindo que estes desafios são os mesmos encontrados por populações rurais, de outras regiões de alta biodiversidade do planeta. Na atualidade, o cenário que se tem é de programas que exploram o valor dos serviços ambientais da floresta sem indícios de sustentabilidade. Executam-se diversos projetos com altos impactos sociais, porém com poucos benefícios para as populações locais. Um exemplo da aplicação de projetos que possam beneficiar os serviços da população amazônica, seria ao em vez de construir mais estradas, impactando o meio ambiente, grande parte da carga na Amazônia pode ser transportada por água. A aplicação destes e outros projetos ambientais representa a melhor alternativa para apoiar a população rural no interior da Amazônia.

Uma pesquisa de estudo de caso $^{(9)}$ destaca as limitações estruturais que impedem o progresso agrícola e explica por que é necessário superar esses impedimentos no Brasil, um dos principais exportadores agrícolas do mundo. O futuro do setor depende do aumento da participação do capital nacional nos negócios e do enfrentamento da estratégia atual e simplista de expansão para novas fronteiras agrícolas, que muitas vezes têm altos custos sociais e ambientais. Estas ações fazem com que o futuro dos agricultores familiares dependa de várias alternativas de desenvolvimento, desafiando as políticas atuais, uma vez que o desenvolvimento atual só enfatiza os grandes produtores rurais. O setor de agricultura familiar também deve ser incluso, pois representa 84,4\% das famílias rurais no Brasil.

Com objetivo identificar, descrever e avaliar fatores presentes em projetos de desenvolvimento sustentável para pequenas comunidades rurais ${ }^{(10)}$, reconhecendo o potencial destes projetos como estratégias de adaptação às mudanças climáticas em pequenas comunidades rurais da região amazônica. Mediante a análise documental de quinze projetos nos 
estados de Rondônia, Pará e Mato Grosso, revelam que a participação da comunidade na tomada de decisões é de suma importância. Constata-se na execução destes projetos, duas estratégias e práticas pertinentes: a organização social e o processo de conscientização e treinamento da comunidade, e a diversificação dos tipos e formas de produção agrícola, aliando o bem estar da população e a conservação do meio ambiente.

Uma pesquisa com objetivo é compreender os padrões temporais e espaciais da intensificação de culturas e pastagens nas fronteiras agrícola-florestal no contexto de mudanças nas políticas de conservação e desenvolvimento rural, um trabalho foi desenvolvido no estado Mato Grosso, por se tratar do maior produtor de soja e gado no Brasil, e também pelo fato de abranger os biomas do Cerrado e da Amazônia ${ }^{(14)}$, o que consequentemente apresenta os níveis mais altos de desmatamento para expansão agrícola. Pode-se inferir através do levantamento, que a intensificação da formação de terras agrícolas e pastagens está ligada ao aumento restrições de conservação florestal. Esses resultados demonstram que a população local de fronteira, acaba sendo exposta aos processos de exploração dos recursos naturais, sem, na maioria das vezes ter como combater tais ações.

Um estudo realizado na comunidade ribeirinha do rio Tocantins de Palmatuba ${ }^{(15)}$, em Babaçulândia/TO, atingida pelo reservatório da UHE de Estreito, teve como objetivo analisar a política energética brasileira frente ao crescimento econômico nacional e como a construção de barragens influenciou o modo de vida de comunidades atingidas na Amazônia, sobretudo no processo de reivindicação das indenizações. Os resultados evidenciaram que no caso da UHE Estreito ocorreram apropriações indevidas, assim como há casos de indenizações que não chegaram à população. Os pesquisadores sugerem como outra alternativa que poderia resolver, mesmo parcialmente, o problema energético e dos povos tradicionais e camponeses em questão, seria a implantação de políticas energéticas que visassem o uso alternativo do coco babaçu, abundante na região para a produção elétrica, diminuindo a construção de barragens e impactando menos sociedade e ambiente.

Outro estudo, realizado no Pantanal ${ }^{(17)}$, utilizando dados de uma etnografia, teve como objetivo discutir como os ambientalistas usaram a Política Nacional para o Desenvolvimento Sustentável dos Povos e Comunidades Tradicionais PNDSPCT, para justificar o deslocamento da população local, alegando que ela não se encaixa em nenhuma comunidade tradicional, que ao invés disso, deveria ser enquadrada como "pobre rural". As evidências baseadas em entrevistas com essas comunidades mostram o contrário, apontando práticas costumeiras que garantem o uso sustentável e o autoreconhecimento como um grupo culturalmente diferenciado.

Um estudo que utilizou como exemplo dois tipos de desastres (intensivo e extensivo) e avaliou dois países com condições de vulnerabilidade sócio-ambiental bastante diferentes: Haiti (terremoto) e Região Serrana do Rio de Janeiro (chuvas fortes) ${ }^{(21)}$. Neste contexto, políticas de redução de riscos de desastres e construção da resiliência constituem prioridades na agenda do desenvolvimento sustentável, estando entre os temas eleitos para a Rio+20. A discussão aponta como a vulnerabilidade socioambiental cria condições para os desastres, ao mesmo tempo em que limita as estratégias para prevenção e mitigação. Os resultados apontam alguns dos desafios que a redução de riscos de desastres e a construção da resiliência exigem em contextos de vulnerabilidade socioambiental.

Um estudo que abrange a sustentabilidade em relação aos biocombustíveis ${ }^{7}$, através da uma revisão sistemática da literatura, embasa os impactos que podem ocorrer no meio econômico, social e ambiental relacionado a políticas públicas e elaboração de projetos sobre esse tema. Vários estudos apontam a necessidade de fornecer avaliações que abrangem a sustentabilidade em relação aos biocombustíveis. No entanto, frequentemente é encontrado na literatura uma maior preocupação ambiental e econômica, em contraste aos aspectos sociais. Os resultados indicam que o desenvolvimento do etanol pode aumentar os níveis de vulnerabilidade social. Os formuladores de políticas públicas precisam internalizar a dimensão social na tomada de decisões. 
$\mathrm{Na}$ Romênia, um estudo teve como objetivo analisar o uso dos biocombustíveis ${ }^{(16)}$, reconhecendo os benefícios positivos da sua utilização. Apesar do fato da Romênia não ter uma produção significativa de biocombustível, o status de Estado Membro da União Européia traz regulamentações comunitárias relativas ao tema, e nesse sentido, a Romênia atrai cada vez mais o interesse de investidores estrangeiros nesse setor. $\mathrm{O}$ estudo sugere que a produção de bioetanol a partir de usinas, a curto prazo, pode contribuir para a diminuição da poluição e aumento de empregos, nesse sentido, o desempenho na área rural se tornou um espaço mais viável, através da perspectiva econômica, social e ecológica.

\subsubsection{Análise dos trabalhos que destacaram a Gestão como eixo do Desenvolvimento Rural Sustentável.}

No Quadro 2 foram selecionados 9 dentre os 19 trabalhos nos quais a Gestão é o eixo do Desenvolvimento Rural Sustentável.

Quadro 2 - Gestão de práticas associadas ao Desenvolvimento Rural Sustentável.

\begin{tabular}{|c|c|c|}
\hline TÍTULO & OBJETIVO & METODOLOGIA \\
\hline $\begin{array}{l}\text { 05- Barômetro da } \\
\text { Sustentabilidade aplicado a } \\
\text { assentamentos rurais do } \\
\text { leste do Estado do Pará, } \\
\text { Brasil. }\end{array}$ & $\begin{array}{l}\text { O presente trabalho tem por objetivo, então, analisar o nível } \\
\text { de sustentabilidade dos assentamentos do Pará, Brasil, por } \\
\text { meio da ferramenta Barômetro da Sustentabilidade (BS). }\end{array}$ & $\begin{array}{l}\text { Empírico- Estudo de caso - } \\
\text { Assentamentos Rurais } \\
\text { localizados no leste do Pará. } \\
\text { Análise documental. } \\
\text { Barômetro da } \\
\text { Sustentabilidade. }\end{array}$ \\
\hline $\begin{array}{ll}\text { 06- } & \text { Beekeeping and } \\
\text { Agroecological } & \text { Systemsfor } \\
\text { Endogenous } & \text { Sustainable } \\
\text { Development. } & \end{array}$ & $\begin{array}{l}\text { Examina o processo de pesquisa agroecológica em sistemas } \\
\text { de apicultura, desenvolvido em conjunto pelo Programa de } \\
\text { Agricultura Temperada da Empresa Brasileira de Pesquisa } \\
\text { Agropecuária (EMBRAPA) e pelo Instituto de Sociologia e } \\
\text { Estudos Camponeses (ISEC), da Universidade de Córdoba. }\end{array}$ & $\begin{array}{l}\text { Empírico- Estudo de caso- } \\
\text { Pesquisa-ação participativa - } \\
\text { aplicada em quatro } \\
\text { experiências produtivas } \\
\text { diferentes no sul do Rio } \\
\text { Grande do Sul, Brasil. }\end{array}$ \\
\hline $\begin{array}{l}\text { 11- Does the Establishment } \\
\text { of Sustainable Use Reserves } \\
\text { Affect Fire Management in } \\
\text { the Humid Tropics? }\end{array}$ & $\begin{array}{l}\text { Analisar dados de reserva, incêndios, chuvas e outras } \\
\text { formas de gestão da terra podem estar prejudicando } \\
\text { efetividade as reservas de uso sustentável (SURs) em } \\
\text { atender à sua conservação e desenvolvimento sustentável } \\
\text { na Amazônia. }\end{array}$ & $\begin{array}{l}\text { Empírico- estudo de caso na } \\
\text { Amazônia - análise } \\
\text { documental }\end{array}$ \\
\hline $\begin{array}{l}\text { 12- Ethanol production } \\
\text { from } \quad \text { molasses: } \\
\text { Environmental and } \\
\text { socioeconomic prospects in } \\
\text { Pakistan: Feasibility and } \\
\text { economic analysis. }\end{array}$ & $\begin{array}{l}\text { Analisar os aspectos ambientais, econômicos e sociais } \\
\text { produção de bioetanol para o desenvolvimento sustentável } \\
\text { da sociedade. }\end{array}$ & $\begin{array}{l}\text { Empírico - estudo de caso } \\
\text { Paquistão - análise } \\
\text { documental }\end{array}$ \\
\hline $\begin{array}{l}\text { 13- Infrastructure is a } \\
\text { necessary but insufficient } \\
\text { condition to eliminate } \\
\text { inequalities in access to } \\
\text { water: Research of a rural } \\
\text { community intervention in } \\
\text { Northeast Brazil. }\end{array}$ & $\begin{array}{l}\text { Este trabalho avalia as condições de acesso à água e as } \\
\text { desigualdades relacionadas antes e após a construção de um } \\
\text { Sistema de Abastecimento de Água (WSS) em uma } \\
\text { comunidade rural da região semi-árida do Brasil. }\end{array}$ & $\begin{array}{l}\text { Empírico - estudo de caso } \\
\text { comunidade rural da região } \\
\text { semi-árida do Brasil - grupo } \\
\text { experimental de controle. }\end{array}$ \\
\hline $\begin{array}{l}\text { 18- Towards } \text { social } \\
\text { sustainability: Screening } \\
\text { potential social and } \\
\text { governance issues for biojet } \\
\text { fuel supply chains in Brazil. }\end{array}$ & $\begin{array}{l}\text { Identificar as questões sociais e de governança mais } \\
\text { importantes e relevantes para o setor de biocombustíveis e } \\
\text { também determinar as questões pelas quais dados } \\
\text { confiáveis e métodos práticos podem estar disponíveis e } \\
\text { simplificados. }\end{array}$ & $\begin{array}{l}\text { Empírico - estudo de caso - } \\
\text { cadeia de suprimentos de } \\
\text { biocombustível do Brasil. }\end{array}$ \\
\hline $\begin{array}{l}\text { 19- Utilising biological } \\
\text { geotextiles: introduction to } \\
\text { the } \quad \text { borassus } \\
\text { project and global } \\
\text { perspectives. }\end{array}$ & $\begin{array}{l}\text { Avaliar a eficácia a longo prazo dos tecidos biológicos para } \\
\text { controlar a erosão do solo e avaliar sua sustentabilidade e } \\
\text { viabilidade econômica. }\end{array}$ & $\begin{array}{l}\text { Empírico - estudo de caso - } \\
\text { no "norte industrial" (na } \\
\text { Europa) e no "sul em } \\
\text { desenvolvimento" (África, } \\
\text { América do Sul e sudeste da } \\
\text { Ásia). }\end{array}$ \\
\hline $\begin{array}{l}\text { 20-Values or hypocrisy: the } \\
\text { global reporting initiative } \\
\text { mapping in agricultural } \\
\text { cooperatives in Parana, } \\
\text { Brazil. }\end{array}$ & $\begin{array}{l}\text { Análise dos relatórios ambientais publicados por } \\
\text { cooperativas agrícolas no estado brasileiro do Paraná em } \\
\text { 2013. Avalia o nível de conformidade dos dados reportados } \\
\text { pelas cooperativas com as diretrizes da Global Reporting } \\
\text { Initiative emitida em } 2016 \text {. }\end{array}$ & $\begin{array}{l}\text { Empírico - estudo de caso - } \\
\text { cooperativas do Paraná - } \\
\text { qualitativo. }\end{array}$ \\
\hline
\end{tabular}




\begin{tabular}{|l|l|}
\hline 03- "Vazanteiros em & Apresentar o processo de ambientalização das lutas sociais \\
movimento": o processo de & das comunidades de Pau Preto, Pau de Légua e Quilombo \\
ambientalização de suas & da Lapinha, no Norte de Minas Gerais, que as \\
lutas territoriais no contexto & ressignificaram nos "Vazanteiros em Movimento", além da \\
das políticas de & análise do conflito ambiental territorial, parte da \\
modernização ecológica. & perspectiva da Ecologia Política e da Sociologia Crítica.
\end{tabular}

Fonte: Autores (2020).

Nesta categoria, observadas no Quadro 2, foram analisados os estudos nos quais abordavam a gestão como um importante instrumento para o Desenvolvimento Rural Sustentável. Todos os trabalhos desta categoria são empíricos e analisam através de estudo de caso temas como: sustentabilidades em assentamentos, sistema apícola associado a agroecologia, sustentabilidade em áreas de reservas de uso sustentável, sustentabilidade na produção do etanol, acesso a água para a desenvolvimento sustentável, tecidos biológicos para a produção sustentável, relatórios de sustentabilidade em cooperativas e ambientalização territorial nas lutas sociais. Ao verificar a metodologia desses trabalhos, nota-se que foram utilizados diferentes instrumentos de coleta e análise de dados tais como barômetro da sustentabilidade, pesquisa-ação, análise documental, grupo controle e estudo etnográfico, sendo que em muitos trabalhos utilizaram dois os mais instrumentos para coletar e analisar os dados estudados.

Dos 9 trabalhos desta categoria de análise 7 foram pesquisas realizados no Brasil, sendo que dois desses estudos investigaram a região da Amazônia e os demais as regiões do Paraná, Minas Gerais e Nordeste. Ainda nesta categoria foram investigados casos no Paquistão e na Europa.

No Brasil, na região da Amazônia, um estudo ${ }^{(11)}$, ao analisar a eficácia das áreas de reserva de uso sustentável na gestão dos incêndios promovidos nesta região, identificou que para que haja de fato um resultado positiva nesta ação é imprescindível a intervenção e promocão de ações junto aos pequenos proputores rurais locais em oportunizar mudanças na gestão das práticas de incêndio visando um desenvolvimento sustentável. Outro estudo ${ }^{(5)}$ nesta região analisou os projetos de assentamentos rurais advindos da reforma agrária em relação ao desenvolvimento socioambiental. Quando comparados os dois modelos de assentamentos (tradissional e sustentável), ambos foram avaliados com precariedade de serviços básicos porém no modelo de assentamento sustentável apresentou um maior potencial de sustentabilidade econômica e ambiental, evidenciando a importância de considerar a proposta de estabelecer como prioridade assentamentos sustentáveis.

Dois estudos ${ }^{(12,18)}$, um realizado no Paquistão e outro realizado no Brasil, analisaram a produção do etanol diante do seu potencial para o desenvolvimento sustentável. O estudo realizado no Paquistão ${ }^{(12)}$ identificou a necessidade de criação de políticas nacionais e esforços em conjunto com entidades locais para estabelecer a produção agroindustrial de etanol e aumentar a escala das destilarias, podendo ser comerciado tanto no âmbito local como para a exportação. O estudo realizado no Brasil $^{(18)}$, ao analisar questões sociais e de governança na cadeia agroindustrial do etanol, constatou aspectos relevantes em relação a saúde, segurança humana, direitos trabalhistas e as condições de trabalho porém foi identificado a necessidade de ferramentas confiáveis para mensurar com mais qualidade essas questões.

Um estudo ${ }^{(13)}$ realizado na região do nordeste do Brasil, avaliou as condições de acesso à água e as desigualdades relacionadas antes e após da construção de um Sistema de Abastecimento de Água em uma comunidade rural. Foi evidenciado que são necessárias medidas adicionais, como a implementação de programas educacionais que ajudem a desmistificar o dilema do cloro e mostrando a importância de ter vários pontos de água dentro da casa.

No Brasil, região do Rio Grande do Sul, um estudo(6) ao analisar um sistema de apicultura, considerou que a apicultura em sistemas agroflorestais, com base nos princípios da agroecologia, adaptáveis a diferentes realidades, gerando estilos diferentes de agroflorestação e apicultura, pode contribuir como estratégias locais voltadas a sustentabilidade. 
Ao analisar o processo de ambientalização de comunidades assentadas, um estudo ${ }^{(3)}$ realizado no Brasil, no estado de Minas Gerais, identificou uma nova ordem política e de paradigma, marcados por ações contraditórias do desenvolvimento sustentável.

Um estudo realizado na Europa ${ }^{(1)}$, analisou a eficácia a longo prazo dos tecidos biológicos para controlar a erosão do solo e avaliar sua sustentabilidade e viabilidade econômica. Foi considerado que os tecidos biológicos diminuíram a erosão do solo. Eles são biodegradáveis, fornecem matéria orgânica e nutrientes ao solo e sua permeabilidade os torna adequados para uso em solos coesos.

Objetivando analisar a conformidade dos relatórios de Responsabilidade Socioambiental - RSA em cooperativas agrícolas no Paraná-Brasil, um estudo ${ }^{(2)}$ identificou em seus resultados que as cooperativas ao publicarem os relatórios não são exemplos de demonstração de uma abordagem estratégica e compromisso com os princípios do desenvolvimento sustentável.

\section{Conclusão}

Foi evidenciado que os estudos referentes ao desenvolvimento rural sustentável nos estudos sociológicos é um tema emergente tanto no âmbito nacional como internacional. Apesar da busca ter sido realizada a partir de 1987, as primeiras publicações evidenciadas nesta pesquisa foram a partir de 2011 com um aumento da média dos trabalhos a partir de 2016, demonstrando que vem aumentando o interesse e preocupação em pesquisas da sociologia voltados a desenvolvimento sustentável no âmbito rural.

Verificou-se que apesar dos descritores terem sido escolhidos a partir do recorte da indicação de como versavam os estudos de sociologia do desenvolvimento rural no Brasil, muitos trabalhos não remetiam a pesquisas brasileiras, porém mencionavam o Brasil em exemplos referentes ao desenvolvimento sustentável no âmbito rural, demonstrando assim que este pais é uma referência em relação a esta temática.

A partir da leitura dos trabalhos, estabeleceu-se dois grandes temas que versavam os trabalhos recuperados nesta pesquisa, sendo eles: Políticas Públicas associadas ao Desenvolvimento Rural Sustentável e Gestão associadas ao Desenvolvimento Rural Sustentável. Esta evidencia pode explicar como a sociologia compreende esta temática.

A partir das discussões mencionadas nos trabalhos que tratavam sobre Políticas Públicas associadas ao Desenvolvimento Rural Sustentável verificou-se que a principal contribuição dessas pesquisas, está em propor uma reflexão a respeito das políticas públicas em consonância com a estrutura agrícola, que pode estar relacionado ao desenvolvimento rural sustentável, a conservação ambiental, a redução de riscos e desastres e construção da resiliência, e sobre a necessidade de pensar esse meio a partir de uma nova abordagem sociológica.

Em relação aos trabalhos que discutiam a Gestão associadas ao Desenvolvimento Rural Sustentável, as contribuições dessa categoria propuseram em suas pesquisas uma reflexão de temas que envolvem a sustentabilidade a partir de análise de assentamentos; da gestão da terra; da eficácia de tecidos biológicos no controle da erosão; e temas que apresentam discussões que envolvem questões sociais de governança como a produção de etanol e suas implicações ambientais, econômicas e sociais, do acesso a água relacionado as desigualdades sociais; de pesquisas do sistema agroecológico; dos relatórios ambientais publicados por cooperativas agrícolas; e análise de conflitos ambientais e lutas sociais.

No Brasil, destacam-se as pesquisas na região da Amazônia, na qual visavam a eficácia dos projetos e políticas publicas voltados ao desenvolvimento sustentável. O interesse dos estudos por esta região do Brasil só reforça sua importância para a sustentabilidade do país.

Considerando o tema investigado, tem-se que o Desenvolvimento Rural Sustentável nos estudos da sociologia ainda terá um longo caminho a percorrer para a compreensão desta temática e consequentemente uma maior efetivação das práticas voltadas a sustentabilidade no ambiente rural. Sugere-se que estudos relacionados ao desenvolvimento rural sustentável sejam 
direcionados a temas transversais, como juventude rural, sucessão, empoderamento feminino, novos mercados do alimento e tecnologia aplicada à agricultura familiar.

\section{Referências}

Abramovay, R. (2000). Funções e medidas da ruralidade no desenvolvimento contemporâneo. IPEA. n. 702, IPEA.

Aleixo, B., Pena, J. L., Heller, 1. \& Rezende, S. (2019). Infrastructure is a necessary but insufficient condition to eliminate inequalities in access to water: Research of a rural community intervention in northeast Brazil. Science of the Total Environment, 652: 1445-1455.

Anaya, F.C. (2014). Vazanteiros em movimento": O processo de ambientalização de suas lutas territoriais no contexto das políticas de modernização ecológica. Ciência \& Saúde Coletiva, 19:10, 4041-4050.

Anzilago, M., Panhoca, L., Bezerra, C. A. P., Beuren, I. M. \& Kassai, J. R. (2018). Values or hypocrisy: the global reporting initiative mapping in agricultural cooperatives in Parana, Brazil. Environmental Monitoring and Assessment, 190: 487-497.

Arshad, M., Abbas, M. \& Iqbal, M. (2019). Ethanol production from molasses: Environmental and socioeconomic prospects in Pakistan: Feasibility and economic analysis. Environmental Technology \& Innovation, 14: 1-10.

Boff, L. (2015). Sustentabilidade: o que é e o que não é. (4 ed.), Vozes.

Carmenta, R., Blackburn, G. A., Davies, G., Sassi C., Lima, A., Parry, L., Tych, W. \& Barlow, J. (2016). Does the Establishment of Sustainable Use Reserves Affect Fire Management in the Humid Tropics? Plos One, 11, 2: 1-19.

Chiaravalloti, R. M. (2019). The Displacement of Insufficiently 'Traditional' Communities: Local Fisheries in the Pantanal. Conservation \& Society, 17:2 173183.

Fearnside, P. (2009). Challenges for sustainable development in Brazilian Amazonia. Susteinable Development, 26: 141-149.

Freitas, C. M. De, Carvalho, M. L. De, Ximenes, E. F., Arraes, E. F. \& Gomes, J. O. (2012). Vulnerabilidade socioambiental, redução de riscos de desastres e construção da resiliência - lições do terremoto no Haiti e das chuvas fortes na região serrana, Brasil. Ciência \& Saúde Coletiva, 17:6, 1577-1586.

Garretti, R. D., Koh, I., Lambin, E. F., Kastens, J. H. \& Brown, J. C. (2018). Intensification in agriculture-forest frontiers: land use responses to development and conservation policies in Brazil. Global Environmental Change, 53: 233-243

Godoi, T. G., Búrigo, F. L. \& Cazella, A. A. (2016). A sustentabilidade dos financiamentos do PRONAF para a agricultura familiar. Desenvolvimento e Meio Ambiente, 38: 637-661.

Kamalia, F. P., Borgesb, J. A. R., Osseweijera, P. \& Posada, J. A. (2018). Towards social sustainability: Screening potential social and governance issues for biojet fuel supply chains in Brazil. Renewable and Sustainable Energy Reviews, 92: 50-61.

Martins, S. R. (2001). Agricultura, ambiente e sustentabilidade: seus limites para a América Latina. CD-ROM/EMATER.

Medina, G., Pereira, A. (2017). Curbing enthusiasm for Brazilian agribusiness: The use of actor-specific assessments to transform sustainable development on theground. Applied Geography, 85: 101-112.

Mendes, K. D. S., Silveira, R. C. de C. P \&Galvão, C. M. (2008). Revisão integrativa: método de pesquisa para a incorporação de evidências na saúde e na enfermagem. Enfermagem, 17, 4: 23-19.

Ribeiro, B. E. (2013). Beyond commonplace biofuels: Social aspects of ethanol. Energy Policy, 57: 355-162.

Sachs, I. (1995). Novas estratégias de desenvolvimento. Estudos avançados, 9, 25 : 84-97. https://doi.org/10.1590/s0103-40141995000300004 consultado em $16 / 02 / 2020$.

Sachs, I. (2008). Desenvolvimento includente, sustentável e sustentado. Garamond.

Schneider, S. (2010). Situando o desenvolvimento rural no Brasil: o contexto e as questões em debate. Economia Política, 30: 3, 45-55.

Sieben, A. \& Cleps Junior, J. (2012). Política energética na Amazônia: a UHE estreito e os camponeses tradicionais de Palmatuba/Babaçulândia (TO). Sociedade e Natureza, 24: 2,183-196.

Silva, V. C. S. \& Vieira, I. C. G. (2016). Barômetro da Sustentabilidade aplicado a assentamentos rurais do leste do Estado do Pará, Brasil. Desenvolvimento e Meio Ambiente, 36: 201-221.

Stefanescu-Mihaila. R. O. (2016). Rural Economy and Bioethanol Production. Sustainability, 8: 2-19.

Szlafsztein, C. F. (2014). Development projects for small rural communities in the Brazilian Amazon region as potential strategies and practices of climate change adaptation. Mitigation and Adaptation Strategies for Global Change, 19: 2, 7-84.

Wolff, L. F., \& Gomes, J. C. C. (2015). Beekeeping and Agroecological Systemsfor Endogenous Sustainable Development. Agroecology and Sustainable Food Systems, 39: 416-435. 